\title{
A Prospective Case-control Study on the Comparison of Postoperative Pain Relief with Transdermal Diclofenac Patch and Injection Diclofenac
}

\author{
${ }^{1}$ Sachender Pal Singh, ${ }^{2}$ Devendra K Jain, ${ }^{3}$ Subbhabrata Das, ${ }^{4}$ Sachin Jain
}

\begin{abstract}
Aim: This is a randomized case-control study to know the efficacy of postoperative pain relief with transdermal diclofenac patch $200 \mathrm{mg}$ and comparison with injection diclofenac sodium $75 \mathrm{mg}$.

Materials and methods: A total of 100 patients with head and neck cancer were included in the study and were randomly divided into two groups ( $A$ and $B$ ). Anesthetic procedure was standardized. A transdermal diclofenac diethylamine patch of $200 \mathrm{mg}$ was applied to group A, just before the skin closure. And in group $B$, injection diclofenac was given 8 hourly. In group $A$, injection diclofenac was given on an as-needed basis whenever patient had visual analog scale (VAS) of pain $>5$. Visual analog scale at 2nd, 4th, 8th, 12th, and 24th hour postoperatively was recorded for 5 days. Injection diclofenac needed in groups $A$ and $B$ was recorded for five postoperative days and the mean number of injections of diclofenac per patient per day needed in both groups was calculated.
\end{abstract}

Results: In group A, we needed only 0.96 injections (diclofenac $75 \mathrm{mg}$ )/patient on the first day and no injection was needed further, while in group B, we had to use three injections/day/ patient. Visual analog scale and pain relief were more steady and better in group $A$ as compared with group $B$.

Conclusion: Transdermal patch of diclofenac diethylamine $200 \mathrm{mg}$ is very effective in providing postoperative analgesia and is better than intravenous injection diclofenac $75 \mathrm{mg}$.

Keywords: Diclofenac sodium 75 mg, Head and neck cancer surgery, Postoperative analgesia, Transdermal diclofenac diethylamine patch.

How to cite this article: Singh SP, Jain DK, Das S, Jain S. A Prospective Case-control Study on the Comparison of Postoperative Pain Relief with Transdermal Diclofenac Patch and Injection Diclofenac. Int J Head Neck Surg 2015;6(4):129-133.

Source of support: Nil

Conflict of interest: None

\footnotetext{
${ }^{1}$ Fellow, ${ }^{2-4}$ Assistant Professor

${ }^{1-3}$ Department of Surgical Oncology, Geetanjali Cancer Centre Udaipur, Rajasthan, India

${ }^{4}$ Department of Medical Oncology, Geetanjali Cancer Centre Udaipur, Rajasthan, India
}

Corresponding Author: Sachender Pal Singh, Fellow Department of Surgical Oncology, Geetanjali Cancer Centre Udaipur, Rajasthan, India, Phone: 02942500066, e-mail: sachender123@gmail.com

\section{INTRODUCTION}

Pain is the most common symptom experienced by a patient after surgery. With gradual progress in the world of science, it is considered a vital sign. Mechanical and thermal injury to tissue during surgery leads to substantial postoperative pain after the surgery. In the era of progress of science, we are determined to pay attention to the comfort and compliance of the patient and give him or her pain-free treatment with minimum side effects.

Most frequently prescribed painkillers nowadays are nonsteroidal anti-inflammatory drugs, which act by inhibition of prostaglandin synthesis, by blocking the activity of cyclooxygenase. Analgesic drugs can be delivered in a variety of routes, including oral, parenteral, as well as transdermal.

Oral route carries the risk of hepatic first-pass metabolism and loss of ample quantities of drug (50\%) before it is absorbed systemically. ${ }^{1,2}$ Due to the high plasma concentrations $\mathrm{s}^{3,4}$ after oral administration of tablet diclofenac, there are risk for significant adverse effects, particularly in the gastrointestinal tract and kidney. ${ }^{5,6}$ Parenteral delivery of drugs can be grossly painful and certain adverse effects may follow immediate rise in drug concentration in the plasma. This originates the need of an alternative choice of route of administration for such drugs. Poor bioavailability, short biological halflife, etc., make diclofenac sodium an ideal candidate for transdermal delivery system. Transdermal therapeutic system is defined as a self-contained, discrete dosage form that delivers the drug topically at a controlled rate and maintains drug concentration within the therapeutic window. The advantage of transdermal patch is that it maintains a constant and prolonged drug level, reduces the frequency of dosing, self-administration, and easy termination of medication leading to patient compliance ${ }^{7,8}$ and also reduced incidence of systemic adverse effects due to lower plasma concentrations. ${ }^{9,10}$

\section{AIMS AND OBJECTIVES}

This randomized case-control study was undertaken to evaluate the efficacy of transdermal diclofenac patch diethylamine $200 \mathrm{mg}$ for postoperative analgesia 
compared with injection diclofenac $75 \mathrm{mg}$, in head and neck cancer patients.

\section{MATERIALS AND METHODS}

\section{Inclusion Criteria}

All the patients with head and neck cancer who underwent surgery under general anesthesia in the surgical oncology department of Geetanjali Medical College and Hospital, Udaipur, from April 2014 to March 2015.

\section{Exclusion Criteria}

Patients with clinical features or a history of renal disease, bronchial asthma, peptic ulcer, allergic reaction induced by diclofenac, and who did not gave his or her consent for participation in the study, were excluded from the study.

A total of 100 patients were included in the study after taking consent and were randomly divided into groups $\mathrm{A}$ and $\mathrm{B}$. The anesthetic procedure was standardized. Transdermal diclofenac diethylamine patch $200 \mathrm{mg}$ $\left(75 \mathrm{~cm}^{2}\right)$ was applied to all the patients of group A after proper randomization and consent of patient, on the skin devoid of hair, just before the skin closure. All patients were extubated after the operation. The patch was replaced every day on different sites. Injection diclofenac sodium $75 \mathrm{mg}$ was given intravenously as and when required whenever visual analog scale (VAS) for pain was $>5$ but was not repeated before 8 hours. In group $\mathrm{B}$, injection diclofenac sodium $75 \mathrm{mg}$ was given intravenously eight hourly. Visual analog scale at 2nd, 4 th, 8th, 12th, and 24th hour postoperatively was recorded for 5 days. Injection diclofenac needed in groups A and B was recorded for five postoperative days, and the mean injection of diclofenac per patient per day needed in both groups was calculated.

\section{RESULTS}

Results of the study are shown in Table 1 and Graphs 1 to 3.

\section{DISCUSSION}

For nonsteroidal anti-inflammatory drugs, transdermal route is a recent drug delivery mechanism substituting oral and other forms of drug administration. Via this route, drug absorbs through skin in a steady way and diffuses into capillaries in a consistent manner for systemic absorption, which often remains a goal of therapy. ${ }^{11,12}$ Diclofenac diethyl ammonium patch pharmacokinetic parameters calculated reveal a profile typical of a sustained-release formulation, with the ability to maintain adequate plasma levels for 24 hours (i.e., up to the next application). The amount of the drug bioavailable for targeting the sites of action is lower than

Table 1: t-test values

\begin{tabular}{|c|c|c|c|c|c|c|c|c|c|}
\hline Group & $n$ & Mean & $S D$ & SEm & Mean difference & SEd & $t$ & $d f$ & $p$-value \\
\hline \multicolumn{10}{|l|}{$\mathrm{D} 1 \mathrm{H} 2$} \\
\hline A & 50 & 6.14 & 0.857 & 0.121 & 4.140 & 0.202 & 20.490 & 98 & 0.000 \\
\hline B & 50 & 2.00 & 1.143 & 0.162 & & & & & \\
\hline \multicolumn{10}{|l|}{ D1H4 } \\
\hline A & 50 & 4.88 & 1.136 & 0.161 & 0.880 & 0.203 & 4.328 & 98 & 0.000 \\
\hline B & 50 & 4.00 & 0.881 & 0.125 & & & & & \\
\hline D1H8 & & & & 0 & & & & & \\
\hline A & 50 & 4.50 & 0.707 & 0.100 & -1.500 & 0.167 & -8.971 & 98 & 0.000 \\
\hline B & 50 & 6.00 & 0.948 & 0.134 & & & & & \\
\hline \multicolumn{10}{|c|}{$\mathrm{D} 1 \mathrm{H} 12$} \\
\hline A & 50 & 3.00 & 1.010 & 0.143 & -1.000 & 0.192 & -5.217 & 98 & 0.000 \\
\hline B & 50 & 4.00 & 0.904 & 0.128 & & & & & \\
\hline \multicolumn{10}{|l|}{ D1H24 } \\
\hline A & 50 & 3.00 & 1.050 & 0.148 & -4.000 & 0.187 & -21.350 & 98 & 0.000 \\
\hline $\mathrm{B}$ & 50 & 7.00 & 0.808 & 0.114 & & & & & \\
\hline \multicolumn{10}{|l|}{$\mathrm{D} 2 \mathrm{H} 2$} \\
\hline A & 50 & 2.50 & 1.015 & 0.144 & 1.620 & 0.183 & 8.867 & 98 & 0.000 \\
\hline B & 50 & 0.88 & 0.799 & 0.113 & & & & & \\
\hline \multicolumn{10}{|l|}{$\mathrm{D} 2 \mathrm{H} 4$} \\
\hline A & 50 & 1.98 & 1.097 & 0.155 & -3.020 & 0.197 & -15.338 & 98 & 0.000 \\
\hline B & 50 & 5.00 & 0.857 & 0.121 & & & & & \\
\hline \multicolumn{10}{|l|}{$\mathrm{D} 2 \mathrm{H} 8$} \\
\hline A & 50 & 2.00 & 1.107 & 0.156 & -4.500 & 0.207 & -21.789 & 98 & 0.000 \\
\hline $\mathrm{B}$ & 50 & 6.50 & 0.953 & 0.135 & & & & & \\
\hline
\end{tabular}




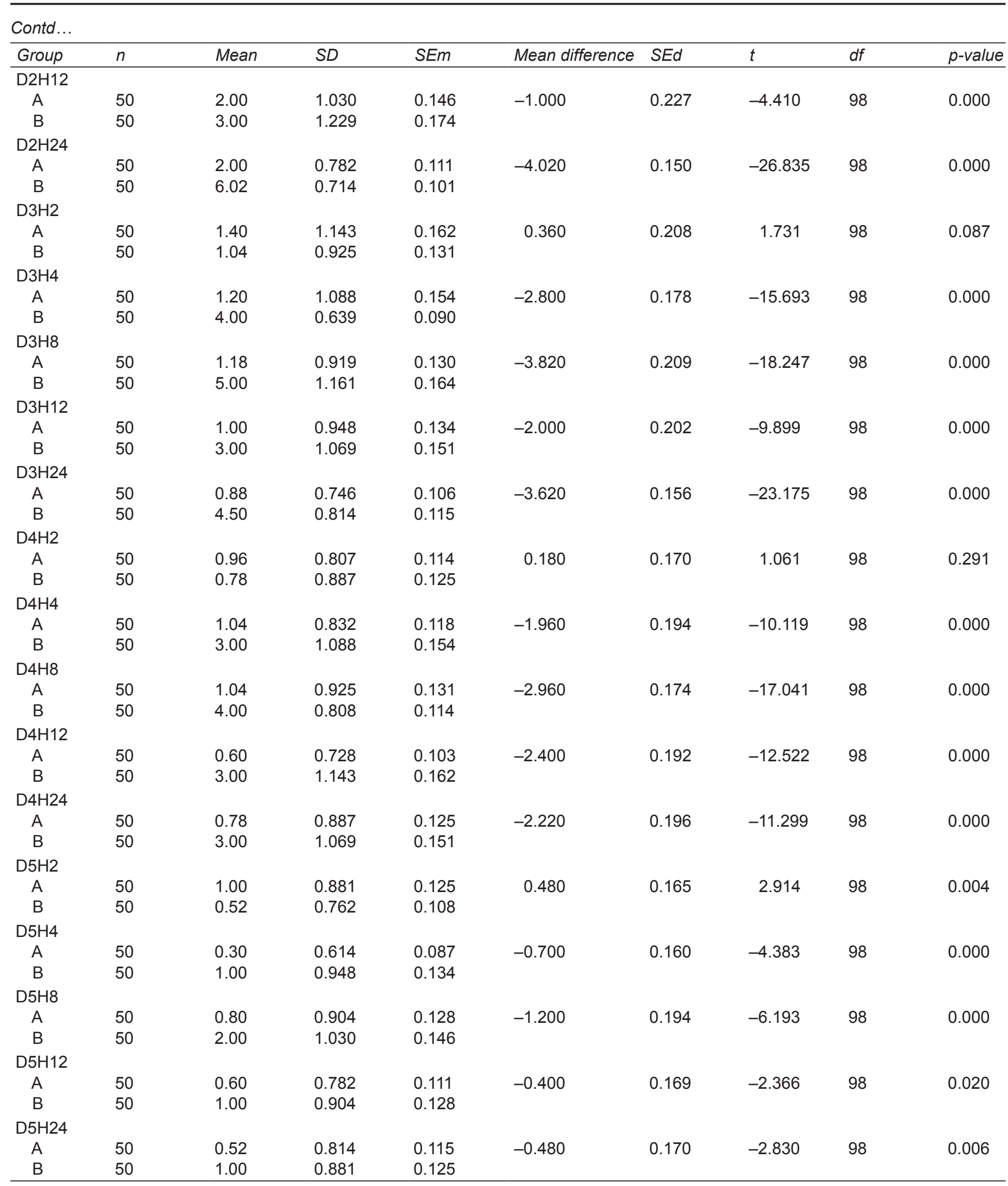

$\mathrm{N}$ : number of patients; SD: standard deviation; SEm: standard error of mean; SEd: standard error of deviation; t: t-test values; df: degrees of freedom; p: p-values; D: postoperative day; $\mathrm{H}$ : hour

via the oral route, but the absorbed dose appears to be adequate for therapeutic use, particularly because of the absence of side effects. ${ }^{13}$

After administration of $75 \mathrm{mg}$ diclofenac by intramuscular injection, peak plasma concentrations of about $2.15 \mu \mathrm{g} / \mathrm{mL}$ are reached after about 20 to 30 minutes. $^{14}$
After intravenous injection, plasma levels of diclofenac fell rapidly and were below the limits of detection at 5.5 hours postdosing. Individual drug profiles were described by a triexponential function, and the mean half-lives of the three exponential phases were $0.05,0.26$, and 1.1 hours. ${ }^{15}$ 
Diclofenac is completely absorbed from the entericcoated tablets after their passage through the stomach. After $150 \mathrm{mg}$ of oral doses of enteric-coated tablets, $72.9 \%$ of the oral dose was absorbed with an average lag time of 2.2 hours. Peak plasma concentrations amounted to $2.9 \mathrm{\mu g} / \mathrm{mL}$ after 3.1 hours. ${ }^{14}$

The mean terminal drug half-life in plasma was 1.8 hours after oral doses. This value was not significantly greater than the value of 1.1 hours following intravenous doses. ${ }^{15}$

The systemic availability of diclofenac from diclofenac sodium slow-release (SR) tablets is on average about $82 \%$ of that achieved with the same dose of diclofenac sodium enteric-coated tablets (possibly due to release rate-dependent first-pass metabolism). As a result of a slower release of the active substance from diclofenac sodium SR tablets, the peak concentrations attained are lower than those observed following the administration of gastro-resistant tablets. Mean peak concentrations of 0.5 or $0.4 \mu \mathrm{g} / \mathrm{mL}(1.6$ or $1.25 \mu \mathrm{mol} / \mathrm{L})$ are reached on average 4 hours after ingestion of a prolonged-release tablet of 100 or $75 \mathrm{mg}$. On the other hand, mean plasma concentrations of $13 \mathrm{ng} / \mathrm{mL}(40 \mathrm{nmol} / \mathrm{L})$ can be recorded at 24 hours (16 hours) after administration of diclofenac sodium SR tablets $100 \mathrm{mg}(75 \mathrm{mg}){ }^{16}$

The results of our study suggest that transdermal diclofenac diethylamine patch $200 \mathrm{mg}$ is better than intravenous diclofenac sodium $75 \mathrm{mg}$ in relieving postoperative pain in head and neck cancer surgeries. As shown in Graph 1, after injection diclofenac sodium in group $B$, there is faster pain relief and mean values of VAS are better than in group A, but it fluctuates as its effects are not steady and decrease with time. But in group A, transdermal patch action is slow in onset but then shows steady response in relieving pain. Patients were more comfortable with this steady action.

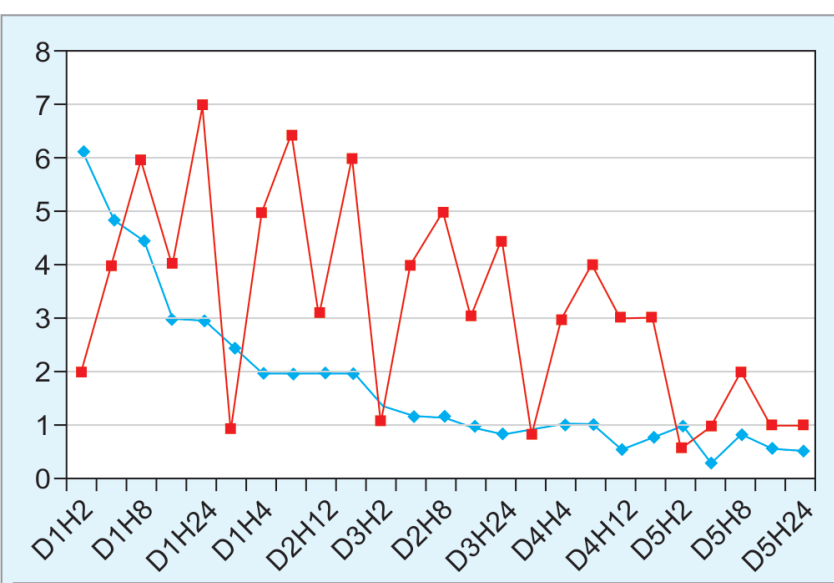

- Mean values of VAS of group A - -Mean values of VAS of group B

Graph 1: Mean values of VAS of groups A and B during postoperative day 1 to 5 . VAS: visual analog scale

Graph 2 also supports the steady action and slow onset of transdermal patch in group A while in group 'B' VAS values keep fluctuating due to faster onset but shorter duration of action of injection diclofenac.

In group A, we needed only 0.96 injections (diclofenac $75 \mathrm{mg}$ )/patient on the first day (Graph 3), and no injections were needed further, while in group B, we had to use three injections/day/patient. So, in this way, we were able to decrease the number of injectables needed for pain relief.

From the table, it can be concluded that differences in the VAS values in both groups and our results are significant and not by chance $(\mathrm{p}<0.05)$.

In summary, transdermal patch is an effective and easy way to deliver postoperative analgesia in head and neck oncological surgeries and is also very safe. With the use of transdermal patch, we were able to reduce the total number of injectable diclofenac sodium $75 \mathrm{mg}$ needed per patient. It did not cause any noticeable adverse events in any of our cases as reported by Agarwal et $a{ }^{17}$ localized erythematous rash or pruritus at the site of application

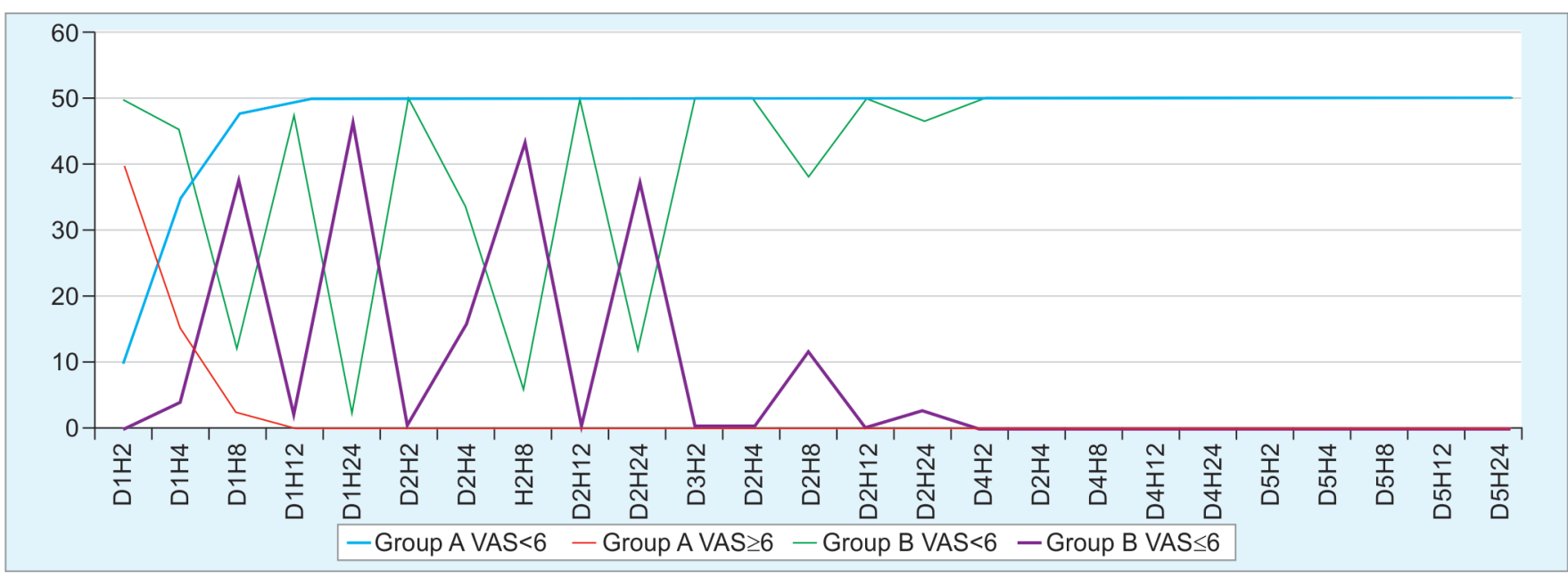

Graph 2: Number of patients in groups A and B with VAS $\leq 6$ 


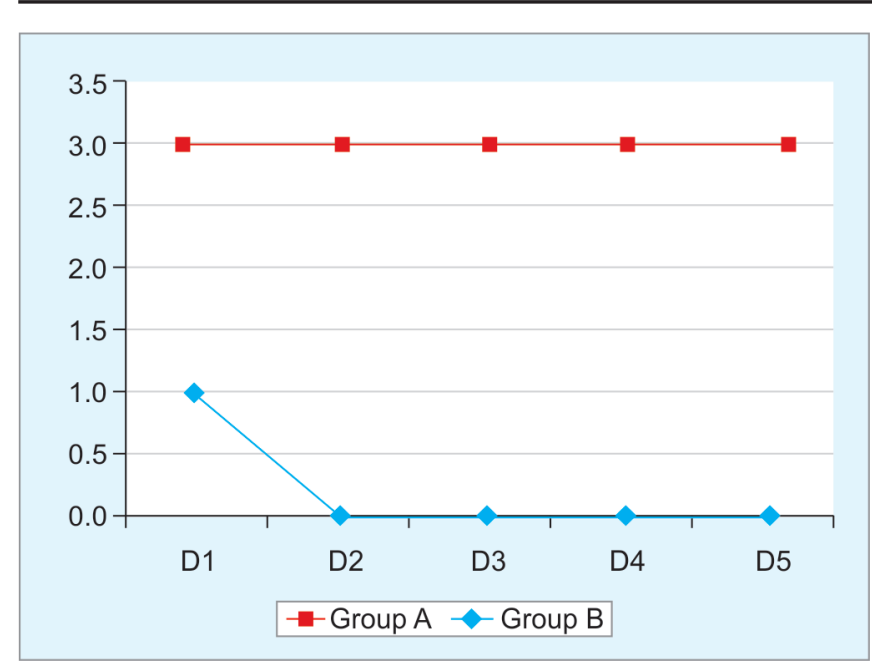

Graph 3: Number of injection Diclofenac $75 \mathrm{mg}$ given per patient in groups $\mathrm{A}$ and $\mathrm{B}$

of the transdermal patch. It may be because we had used different sites on patient body for application of transdermal patch every day.

\section{CONCLUSION}

Transdermal patch of diclofenac diethylamine sodium $200 \mathrm{mg}$ is better than intravenous injection diclofenac sodium $75 \mathrm{mg}$ for postoperative analgesia. Transdermal patch is an easy, effective, comfortable route with a high compliance of the patient, and it does not have the disadvantages or side effects of parenteral or oral diclofenac. But due to slower onset of action, we also recommend intravenous injection diclofenac $75 \mathrm{mg}$ just after the operation on the first postoperative day.

\section{REFERENCES}

1. Chien, YW. Transdermal controlled systemic medication. New York: Marcel Dekker; 1987. p. 159-176.

2. Knutson K, Krill SL, Lambert WJ, Higuchi WI. Physicochemical aspects of transdermal permeation. J Control Release 1987 Dec;6(1):59-74.

3. The Royal College of Anaesthetists. Guidelines for the Use of Non-Steroidal Anti-Inflammatory Drugs in the Perioperative
Period. London: The Royal College of Anaesthetists; March 1998.

4. Heyneman CA, Lawless-Liday C, Wall GC. Oral versus topical NSAIDs in rheumatic diseases-a comparison. Drugs 2000 Sep;60(3):555-574.

5. Naesdal J, Brown K. NSAID-associated adverse effects and acid control aids to prevent them: a review of current treatment options. Drug Saf 2006;29(2):119-132.

6. Roth SH, Shainhouse JZ. Efficacy and safety of a topical diclofenac solution (Pennsaid) in the treatment of primary osteoarthritis of the knee: a randomized, double-blind, vehicle-controlled clinical trial. Arch Intern Med 2004 Oct 11;164(18):2017-2023.

7. Keith AD. Polymer matrix consideration for transdermal devices. Drug Dev Ind Pharm 1983;9(4):605-621.

8. Bertocchi P, Antoniella E, Valvo L, Alimonti S, Memoli A. Diclofenac sodium multisource prolonged release tablets-a comparative study on the dissolution profiles. J Pharm Biomed Anal 2005 Apr 1;37(4):679-685.

9. Cranney A, O'Donnell S. Topical diclofenac improved pain and physical function with no systemic side effects in primary osteoarthritis of the knee. Evid Based Med 2005;10(3):81.

10. Radbruch L. Buprenorphine TDS: use in daily practice, benefits for patients. Int J Clin Pract Suppl 2003 Feb;(133):19-22.

11. Mazieres B. Topical ketoprofen patch. Drugs R D 2005;6(6): 337-344.

12. Tracy $\mathrm{H}$. Breaking barriers in transdermal drug delivery. JAMA 2005 May 4;293(17):2083.

13. Devi K, Paranjothy KL. Pharmacokinetic profile of a new matrix-type transdermal delivery system: diclofenac diethyl ammonium patch. Drug Dev Ind Pharm 1999 May;25(5): 695-700.

14. Kurowski M. Pharmacokinetics and biological availability of diclofenac preparations following intramuscular injection of $75 \mathrm{mg}$ and oral administration of $150 \mathrm{mg}$ of active drug. Z Rheumatol 1988 Jan-Feb;47(1):37-42.

15. Willis JV, Kendall MJ, Flinn RM, Thornhill DP, Welling PG. The pharmacokinetics of diclofenac sodium following intravenous and oral administration. Eur J Clin Pharmacol 1979;16(6):405-410.

16. Voltarol SR and Retard Tablets. Last updated on eMC 22-Jun2014. Available from: http://www.medicines.org.uk/emc/ medicine/1343/SPC/Voltarol+SR+and+Retard+Tablets [cited April 18, 2015].

17. Agarwal A, DhiraajS, Kumar A, Singhal V, Singh U. Evaluation of a Diclofenac transdermal patch for the attenuation of venous cannulation pain: a prospective, randomised, double-blind, placebo-controlled study. Anaesthesia 2006 Apr;61(4):360-362. 